\title{
Erratum to: La détresse des patients gravement malades est-elle mesurable et par qui ?
}

\section{Erratum to: Is the Distress of Critically Patients Measurable and by whom?}

Erratum to: Psycho-Oncol. DOI 10.3166/pson-2018-0016

En page 182, volume 12, numéro 3, septembre 2018, concernant les auteurs et leurs affiliations, il faut lire :
A. Van Lander ${ }^{1,2}$, A. Tarot ${ }^{1}$, C. Savanovitch ${ }^{2}$, B. Pereira ${ }^{3}$, B. Vennat ${ }^{2}$, V. Guastella ${ }^{1}$
${ }^{1}$ Unité de soins palliatifs CHU Clermont Ferrand
${ }^{2}$ UPU ACCePPT Université Clermont Auvergne
${ }^{3}$ DRCI CHU Clermont-Ferrand 